\title{
The effect of dietary zinc deficiency on pancreatic $\gamma$-glutamyl hydrolase (EC 3.4.22.12) activity and on the absorption of pteroylpolyglutamate in rats
}

\author{
BY MARY C. CANTON, B. M. COTTER, F. M. CREMIN AND P. A. MORRISSEY \\ Department of Nutrition, University College, Cork, Irish Republic
}

(Received 12 December 1988 - Accepted 8 March 1989)

\begin{abstract}
The effect of dietary zinc deficiency on $\gamma$-glutamyl hydrolase $(E C$ 3.4.22.12) activity and on pteroylpolyglutamate absorption was investigated in rats. Enzyme activity was determined in pancreas and gut lumen washings. Pteroylpolyglutamate absorption was studied by determining the rise in plasma folate levels following pteroylpolyglutamate ingestion. Two experiments were performed; in each purified diets were given to three groups of immature male Wistar rats for approximately 2 weeks. One group was given a $\mathrm{Zn}$-deficient diet ad lib. (ZD), the second was pair-fed daily with this group on a $\mathrm{Zn}$ adequate diet (PF) and the third was given the $\mathrm{Zn}$-adequate diet ad lib. (AL). In Expt 1, significantly reduced pancreatic $\gamma$-glutamyl hydrolase activity was observed in ZD rats. In Expt 2, pteroylpolyglutamate was administered on day 14 and in the $3 \mathrm{~h}$ period following pteroylpolyglutamate ingestion, lumen $\gamma$-glutamyl hydrolase activity and plasma folate levels were significantly lower in ZD rats. Pancreas is reported as the source of lumen $y$-glutamyl hydrolase in rats. The results presented indicate that the pancreatic enzyme is $\mathrm{Zn}$-sensitive. It was concluded that, as a result, $\gamma$-glutamyl hydrolase activity was reduced in the lumen of $\mathrm{ZD}$ rats. Consequently the hydrolysis and subsequent absorption of pteroylpolyglutamate was impaired in $\mathrm{ZD}$ rats, as indicated by the smaller rise in plasma folate levels that occurred following pteroylpolyglutamate ingestion. Results of this study concur with previous observations in human beings and rats that $\mathrm{Zn}$ deficiency has an adverse effect on folate metabolism.
\end{abstract}

Folate metabolism: Zinc: Rat.

Dietary folates exist predominantly as a mixture of pteroylpolyglutamates (Butterworth et al. 1963) based on the 4-[(pteridin-6-ylmethyl)amino] benzoic acid skeleton conjugated with one or more L-glutamate units (Blakley, 1987). Intestinal absorption requires hydrolysis of the poly- $\gamma$-glutamyl side-chain to the absorbable mono- or diglutamyl derivative (Butterworth et al. 1969; Baugh et al. 1971). Hydrolysis is mediated by $\gamma$ glutamyl hydrolase (EC 3.4.22.12), commonly known as folate conjugase (Halsted, 1979).

Several studies have suggested an interaction between zinc and folate metabolism. Silink et al. (1975) observed that $\mathrm{Zn}$ is essential for the stability of purified bovine liver $\gamma$-glutamyl hydrolase. Human jejunal brush-border membrane $\gamma$-glutamyl hydrolase is activated by $\mathrm{Zn}$ (Dwivedi et al. 1983; Halsted et al. 1983, 1985; Wang et al. 1985; Chandler et al. 1986), and $\mathrm{Zn}$ was observed to stimulate activity in the supernatant fraction of rat intestinal mucosa (Day \& Gregory, 1984). The latter finding was not confirmed by Wang et al. (1985). Several studies in human beings indicate that folate supplements adversely affect $\mathrm{Zn}$ metabolism (Milne et al. 1984; Lukaski et al. 1986; Sandstead et al. 1987; Simmer et al. 1987). In the rat, Wilson et al. (1983) suggested that folate competitively inhibits $\mathrm{Zn}$ absorption, and Ghishan et al. (1986) reported mutual inhibition between $\mathrm{Zn}$ and folate at the site of intestinal transport. Other studies do not indicate an adverse effect of folate on $\mathrm{Zn}$ metabolism in human beings (Wada et al. 1986; Keating et al. 1987; Butterworth et al. 1988) and in rats (Wada et al. 1986; Keating et al. 1987; Fuller et al. 1988). A number of 
studies have suggested that $\mathrm{Zn}$ deficiency affects folate metabolism. Reduced liver (Williams et al. 1973) and plasma (Tamura et al. 1987) folate concentrations have been observed in Zn-deficient rats. Fuller et al. (1988) observed that $\mathrm{Zn}$ supplementation enhanced blood folate levels in rats. Impaired absorption of pteroylpolyglutamates, but not monoglutamates, was reported in Zn-depleted human beings (Tamura et al. 1978) and in aged rats (Kesavan \& Noronha, 1983). Tamura et al. (1978) suggested that in man, intestinal $\gamma$-glutamyl hydrolase is a $\mathrm{Zn}$-dependent enzyme, and that during $\mathrm{Zn}$ depletion its activity is decreased, resulting in reduced pteroylpolyglutamate absorption. Two separate intestinal $\gamma$-glutamyl hydrolases have been identified in man, one intracellular and the other located on the brush-border membrane (Reisenauer et al. 1977). The latter has been characterized as a $\mathrm{Zn}$-activated exopeptidase and Chandler et al. (1986) reported that it, rather than the intracellular enzyme, is essential for the hydrolysis of dietary folates. Kesavan \& Noronha (1983) observed decreased $\gamma$-glutamyl hydrolase activity in the pancreas and gut lumen of aged rats. They suggested that, in rats, pancreas is the source of lumen $\gamma$-glutamyl hydrolase.

In the present study $\gamma$-glutamyl hydrolase activity in the pancreas and gut lumen of $\mathrm{Zn}$ deficient rats was investigated. The effect of $\mathrm{Zn}$ deficiency on pteroylpolyglutamate absorption was also investigated by determining the increase in plasma folate levels following ingestion of a yeast pteroylpolyglutamate preparation.

\section{MATERIALS AND METHODS}

\section{Animals and diets}

Two animal experiments were performed, involving twenty-seven rats in Expt 1 and ninety rats in Expt 2. Male weanling Wistar rats were obtained from the Biological Services Unit, University College, Cork, and maintained on commercial chow diet (balanced ration; William Connolly \& Sons Ltd, Red Mills, Goresbridge, Co. Kilkenny) for approximately 1 week after delivery to our laboratory. Rats in each experiment were randomly allocated into three groups of similar mean weight. Each group was placed on one of three dietary regimens. The first group was fed on a $\mathrm{Zn}$-deficient diet ad lib. (Zn-deficient; $\mathrm{ZD}$ ), and the second group was fed ad lib. on a $\mathrm{Zn}$-adequate diet (ad lib.-fed controls; AL). The third group was fed on the $\mathrm{Zn}$-adequate diet, but each rat received daily the same amount of diet as consumed by a rat in the $\mathrm{Zn}$-deficient group on the previous day (pair-fed controls; PF). Diets were formulated as shown in Table 1. The duration of Expt 1 was $16 \mathrm{~d}$ and the concentration of $\mathrm{Zn}$ in deficient and control diets was determined by analysis as 3.0 and $77.0 \mathrm{mg} / \mathrm{kg}$ diet respectively. The duration of Expt 2 was $14 \mathrm{~d}$ and on analysis, the $\mathrm{Zn}$ contents of the diets were 2.5 and $90.0 \mathrm{mg} / \mathrm{kg}$ in deficient and control diets respectively. All rats received distilled water ad lib., daily food intake was recorded and animals were weighed every 4-5 d. Rats were kept in individual plastic cages fitted with stainless-steel bottoms and lids. Before each experiment, cages, hoppers and glass water bottles (fitted with melamine caps) were thoroughly detergent-washed and rinsed in distilled water to minimize $\mathrm{Zn}$ contamination. The room in which rats were housed was maintained at $22 \pm 2^{\circ}$; a continuous air-flow system and a $12 \mathrm{~h}$ light $-12 \mathrm{~h}$ dark cycle were operated.

On day 16, following overnight fasting, the rats in Expt 1 were lightly anaesthetized and blood was withdrawn by retro-orbital puncture of the subretinal vein, using heparinized capillary tubes. Plasma was prepared by centrifugation and portions stored in new plastic tubes at $-20^{\circ}$. Rats were killed by cervical dislocation, the pancreas was removed, frozen in liquid nitrogen and stored at $-20^{\circ}$ for later measurement of pancreatic $\gamma$-glutamyl hydrolase activity. The right tibia of each rat was excised and stored at $-20^{\circ}$ for later measurement of $\mathrm{Zn}$ concentration. 
Table 1. Composition of diets $(\mathrm{g} / \mathrm{kg})$

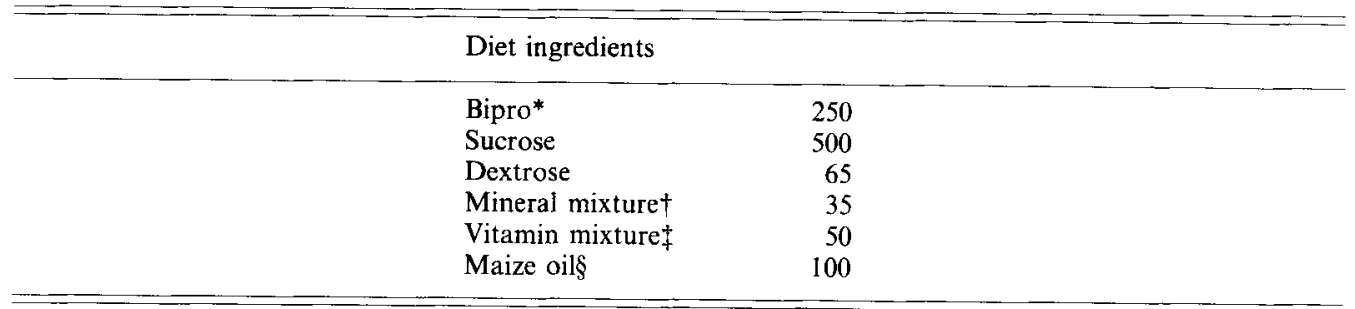

* Bipro is a whey protein manufactured by Mitchelstown Creameries, Co. Cork, Irish Republic, containing about $13 \mathrm{mg} \mathrm{Zn} / \mathrm{kg}$ and $920 \mathrm{~g}$ protein of biological value similar to that of egg protein $/ \mathrm{kg}$.

$\dagger$ Mineral mixture (American Institute of Nutrition, 1977) without zinc carbonate. Composition of $\operatorname{mix}(\mathrm{g} / \mathrm{kg})$ : calcium hydrogen phosphate 500 , sodium chloride 74 , potassium citrate monohydrate 220 , potassium sulphate 52 , magnesium oxide 24 , manganous carbonate $3 \cdot 5$, ferric citrate 6 , potassium iodate 0.01 , sodium selenite $0 \cdot 01$, chromium potassium sulphate 0.55 , cupric carbonate 0.3 . Sucrose was added to $1 \mathrm{~kg}$. Zinc was added as the carbonate to the required level for each control diet.

\$ Vitamin mixture, recommended by Queen Elizabeth College, London, and modified by D. A. Bender (personal communication). Composition of $\operatorname{mix}(\mathrm{g} / \mathrm{kg})$ : ascorbic acid $3 \cdot 75$, nicotinic acid 3 , vitamin $\mathrm{B}_{12}\left(0^{\cdot} \cdot 1 \%\right)$ 0.04 , calcium pantothenate 2 , thiamin hydrochloride 0.5 , riboflavin 5 -phosphate 0.5 , pyridoxine hydrochloride 0.5 , pteroylmonoglutamic acid 0.2 , biotin 0.5 , menadione 0.5 , Rovimix $\mathrm{A} / \mathrm{D}_{3}(150 \mathrm{mg}$ vitamin $\mathrm{A}$ and $2.5 \mathrm{mg}$ vitamin D/g) $0 \cdot 4$, Rovimix E (500 mg/g) $7 \cdot 5$, choline chloride 90 , cellulose 891 .

$\S$ Mazola $^{\mathbb{E}}$ Pure Corn Oil; CPC Ltd, Esher, Surrey.

On days 11, 12 and 13, rats in Expt 2 were administered intraperitoneally $80 \mu \mathrm{g}$ pteroylmonoglutamic acid $/ \mathrm{kg}$ body-weight in order to minimize variations in initial folate status. On day 14 , following overnight fasting, each group of thirty rats was divided into five subgroups of six. Rats were administered intragastrically $40 \mu \mathrm{g}$ yeast pteroylpolyglutamate $/ \mathrm{kg}$ body-weight. Pteroylpolyglutamate was prepared from yeast, as described by Perry \& Chanarin (1968) and found to contain 102 (SE 6.0) mg folate $/ \mathrm{kg}$. One subgroup from each group was bled at $0,0 \cdot 5,1,2$ and $3 \mathrm{~h}$ after pteroylpolyglutamate ingestion and plasma was prepared as described previously. Small intestines were removed and divided into four segments of equal length. The lumen contents of the proximal segment were washed out with $10 \mathrm{ml}$ ice-cold $0.25 \mathrm{M}$-sucrose solution and stored at $-20^{\circ}$.

\section{Analytical procedures}

$\mathrm{Zn}$ concentrations in diets, plasma and tibia were determined by flame atomic absorption spectroscopy (Pye Unicam SP9 Model). Diets and tibia were digested in a mixture $(2: 1$; $\mathrm{v} / \mathrm{v}$ ) of Analar grade concentrated nitric and perchloric acids (BDH Chemicals Ltd, Poole, Dorset) on a hot plate until the colour resembled that of the reagent blanks. Samples were made to volume (variable) with distilled water. Aqueous $\mathrm{Zn}$ standards were prepared by dilution of $\mathrm{Zn}$ nitrate stock solution (Spectrosol; BDH Chemicals Ltd). Before digestion tibia were cleansed of soft tissue and dried overnight at $105^{\circ}$ to a constant weight. Plasma was diluted with distilled water $(1: 4)$ and $\mathrm{Zn}$ standards were prepared in glycerol $(50 \mathrm{ml} / \mathrm{l})$.

Plasma folate concentrations were measured microbiologically by the method of Scott et al. (1974) as modified by Wilson \& Horne (1982) using Lactobacillus casei (ATCC 7469). Pancreatic $\gamma$-glutamyl hydrolase activity was determined by a modification of the method of Kesavan \& Noronha (1983). An homogenate of pancreas $(100 \mathrm{mg} / \mathrm{ml})$ was prepared in ice-cold $0.25 \mathrm{~m}$-sucrose using a Potter-Elvehjem glass tube and Teflon pestle. The homogenates were centrifuged at $8600 \mathrm{~g}$ for $15 \mathrm{~min}$ at $4^{\circ}$ using a Sorvall RC-5B centrifuge. The supernatant fraction was removed by micropipette, portions transferred to new plastic tubes and stored at $-20^{\circ}$ until required. To determine pancreatic $\gamma$-glutamyl hydrolase 
Table 2. Expts 1 and 2. Body-weight changes, food intake and food conversion efficiency values of zinc-deficient $(Z D)$ rats and their pair-fed $(P F)$ and ad lib.-fed $(A L)$ controls

(Mean values and standard deviations)

\begin{tabular}{l}
\hline \\
\hline
\end{tabular}

NS, not significant.

* For details of diets, see p. 186 and Table 1.

$\dagger \mathrm{g}$ body-weight gain/g food eaten.

activity the following reagents were added to new glass tubes: $0.7 \mathrm{ml} 0.1 \mathrm{M}$-acetate buffer, pH 4.1, ascorbate $(10 \mathrm{~g} / 1), 0.1 \mathrm{ml} \beta$-mercaptoethanol $(100 \mathrm{ml} / 1$ buffer $)$ and $0.2 \mathrm{ml}$ yeast extract ( $300 \mathrm{mg}$ made to $100 \mathrm{ml}$ with buffer). The reaction was initiated by adding $5-10 \mu 1$ pancreas supernatant fraction. The mixture was incubated in a water-bath at $37^{\circ}$ for $20 \mathrm{~min}$ and the reaction terminated by heating in a boiling water-bath for $10 \mathrm{~min}$. Blanks were prepared by heating the mixture (excluding yeast extract) in a boiling water-bath for 10 min, cooling, adding the yeast extract and incubating at $37^{\circ}$ for $20 \mathrm{~min}$. Samples were later analysed microbiologically for free folate. Enzyme activity was expressed as ng folate released $/ \mathrm{mg}$ protein per $20 \mathrm{~min}$. Lumen $\gamma$-glutamyl hydrolase was similarly determined. The protein concentration of homogenates and lumen solutions was determined by the method of Lowry et al. (1951).

\section{Statistical analysis}

Means, standard deviations and the significance values $(P)$ were calculated using the Minitab Statistical Package (Ryan et al. 1976) in a Vax computer (Model 11/780).

\section{RESULTS}

In both experiments anorexia and a cyclic eating pattern were observed in rats fed on the $\mathrm{Zn}$-deficient diet for 3-4 d. Consequently, food intake was significantly $(P<0.001)$ 
Table 3. Expt 1. The effect of zinc deficiency on plasma $(\mathrm{mg} / \mathrm{l})$ and tibia $(\mu \mathrm{g} / \mathrm{g}) \mathrm{Zn}$ concentrations* and pancreatic $\gamma$-glutamyl hydrolase (folate conjugase, EC 3.4.22.12) activity in $\mathrm{Zn}$-deficient $(Z D)$ rats and their pair-fed $(P F)$ and ad-lib.-fed $(A L)$ controls

(Mean values and standard deviations)

\begin{tabular}{|c|c|c|c|c|c|c|}
\hline \multirow[b]{2}{*}{$\begin{array}{l}\text { Dietary group } \dagger . \\
n \ldots\end{array}$} & & \multirow[b]{2}{*}{$\begin{array}{c}\text { ZD } \\
9\end{array}$} & \multirow[b]{2}{*}{$\begin{array}{l}\text { PF } \\
9\end{array}$} & \multirow[b]{2}{*}{$\begin{array}{c}\mathrm{AL} \\
9\end{array}$} & \multicolumn{2}{|c|}{$\begin{array}{l}\text { Statistical significance of } \\
\text { difference from ZD group: } P\end{array}$} \\
\hline & & & & & $\mathrm{PF}$ & $\mathrm{AL}$ \\
\hline \multicolumn{7}{|c|}{ Plasma Zn (mg/l) } \\
\hline & $\begin{array}{l}\text { Mean } \\
\text { SD }\end{array}$ & $\begin{array}{l}1.27 \\
0.09\end{array}$ & $\begin{array}{l}1 \cdot 81 \\
0 \cdot 14\end{array}$ & $\begin{array}{c}1.80 \\
0.21\end{array}$ & $<0.001$ & $<0.001$ \\
\hline Tibia $\operatorname{Zn}(\mu \mathrm{g} / \mathrm{g})$ & $\begin{array}{l}\text { Mean } \\
\text { SD }\end{array}$ & $\begin{array}{r}115 \cdot 9 \\
10 \cdot 3\end{array}$ & $\begin{array}{r}248 \cdot 8 \\
21.9\end{array}$ & $\begin{array}{r}261 \cdot 5 \\
11 \cdot 5\end{array}$ & $<0.001$ & $<0.001$ \\
\hline \multicolumn{7}{|c|}{$\begin{array}{l}\gamma \text {-Glutamyl hydrolase } \\
\text { activity (ng folate } \\
\text { per mg protein } / 20 \mathrm{~min} \text { ) }\end{array}$} \\
\hline & $\begin{array}{l}\text { Mean } \\
\text { SD }\end{array}$ & $\begin{array}{r}330 \cdot 0 \\
30 \cdot 0\end{array}$ & $\begin{array}{r}790 \cdot 0 \\
50 \cdot 0\end{array}$ & $\begin{array}{l}830 \cdot 0 \\
100 \cdot 0\end{array}$ & $<0.001$ & $<0.001$ \\
\hline
\end{tabular}

* Concentrations (/g dry weight).

$\dagger$ For details of diets, see p. 186 and Table 1.

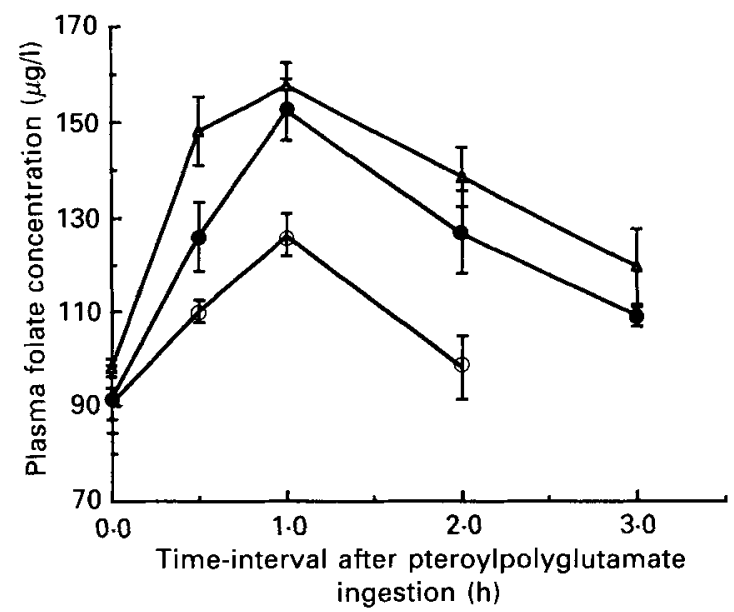

Fig. 1. Expt 2. Plasma folate concentrations $(\mu \mathrm{g} / \mathrm{l})$ in rats after intragastric administration of yeast pteroylpolyglutamate. Points are means, and standard errors represented by vertical bars, for: $(O)$, Zn-deficient ; $(\bullet)$, pair fed controls; $(\triangle)$, ad-lib.-fed controls; for details of diets, see p. 186 and Table 1.

reduced for the $\mathrm{ZD}$ and $\mathrm{PF}$ groups compared with the AL (control) group (Table 2). Significant reductions in food conversion efficiency $(P<0.001 ; P<0.02)$ and weight gain $(P<0.001 ; P<0.05)$ were observed in ZD groups compared with PF groups in Expts 1 and 2 respectively (Table 2 ).

Table 3 shows the effect of $\mathrm{Zn}$ deficiency on tissue $\mathrm{Zn}$ levels and pancreatic $\gamma$-glutamyl hvdrolase activity in Expt 1. Plasma and tibia $\mathrm{Zn}$ concentrations were significantly $(P<$ 
Table 4. $\gamma$-Glutamyl hydrolase (folate conjugase, EC 3.4.22.12) activity* in lumen washings of the proximal intestinal segment of zinc-deficient $(Z D)$ rats and their pair-fed controls $(P F)$ after ingestion of pteroylpolyglutamate

(Mean values and standard deviations)

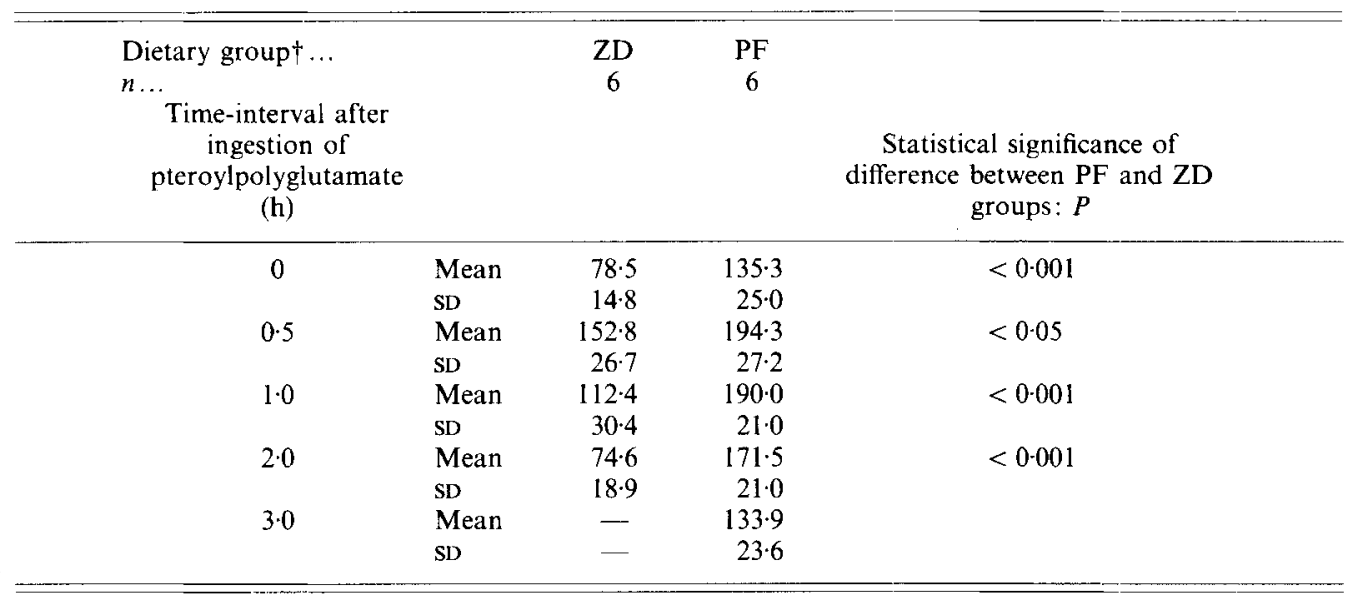

* ng folate $/ \mathrm{mg}$ protein per $20 \mathrm{~min}$.

$\dagger$ For details of diets, see p. 186 and Table 1.

0.001) lower in the ZD group than in the PF and AL controls. No difference was observed in plasma and tibia $\mathrm{Zn}$ levels in the latter groups, indicating that the reduction observed in the ZD group was not due to decreased food intake. Similarly, pancreatic $\gamma$-glutamyl hydrolase activity was significantly $(P<0.001)$ lower in the ZD group than in the PF and AL controls. The results in Fig. 1 are those of the in vivo pteroylpolyglutamate absorption study performed in Expt 2. Baseline plasma folate concentration and changes in plasma folate concentration that occurred at various time-intervals following pteroylpolyglutamate ingestion are indicated. Following ingestion, plasma folate concentration was significantly lower in the ZD group compared with the AL control group at $0.5,1$, and $2 \mathrm{~h}(P<0.001)$ and with the PF control group at 1 and $2 \mathrm{~h}(P<0.01$ and $P<0.03$ respectively). At $2 \mathrm{~h}$ post-ingestion, plasma folate concentration for the ZD group had returned to baseline values. The area under the folate absorption curve for the ZD group represented 26 and $38 \%$ of that obtained for the AL and PF control groups respectively. Table 4 shows the $\gamma$-glutamyl hydrolase activity of the gut lumen washings. The fasting level of gut lumen $\gamma$ glutamyl hydrolase activity in the ZD group was approximately $50 \%$ lower than that for the PF group. Lumen $\gamma$-glutamyl hydrolase activity increased in both groups following pteroylpolyglutamate ingestion, attaining maximal levels within $1 \mathrm{~h}$. Thereafter, activity progressively declined, returning to fasting levels at 2 and $3 \mathrm{~h}$ post-ingestion in the $\mathrm{ZD}$ and $\mathrm{PF}$ groups respectively.

\section{DISCUSSION}

In rats, several authors have reported $\gamma$-glutamyl hydrolase activity in the intracellular supernatant fraction of intestinal mucosal homogenates (Day \& Gregory, 1.984; Elsenhans et al. 1984; Wang et al. 1985). Activity in the brush-border membrane is reported as negligible (Wang et al. 1985). Following oral administration of pteroylpolyglutamate to rats, Jagerstad \& Westesson (1974) observed partially hydrolysed derivatives in the 
stomach and duodenal contents, but the absorbable derivative occurred mainly beyond the point of entry of the pancreatic duct. Consequently, they suggested that $\gamma$-glutamyl hydrolase is secreted from the pancreas into the intestine. Similarly, Kesavan \& Noronha (1983) suggested that lumen $\gamma$-glutamyl hydrolase of pancreatic origin has a greater role in pteroylpolyglutamate digestion than the mucosal enzyme.

The results of Expt 1 indicate that rat pancreatic $\gamma$-glutamyl hydrolase is a $\mathrm{Zn}$-dependent enzyme. In $\mathrm{ZD}$ rats enzyme activity was $60 \%$ lower than in PF and AL controls. The occurrence of $\mathrm{Zn}$ deficiency was indicated by significantly lower plasma and tibia $\mathrm{Zn}$ concentrations in the ZD group compared with both PF and AL control groups (Table 3). Impaired food utilization and a cyclic eating pattern, characteristics of $\mathrm{Zn}$ deficiency in rats (Williams \& Mills, 1970), were also observed. Reduced enzyme activity was not due to decreased food intake, as similar levels of activity were observed in both PF and AL control rats (Table 3 ).

The results of Expt 2 confirm the observation of Tamura et al. (1978) that dietary $\mathrm{Zn}$ deprivation adversely affects pteroylpolyglutamate absorption. The protocol for Expt 1 was repeated to ensure the development of a similar state of $\mathrm{Zn}$ deficiency. At zero-time all groups exhibited similar plasma folate concentrations, since all were supplemented with pteroylmonoglutamic acid for $3 \mathrm{~d}$ before the absorption study. Compared with PF and AL control groups, pteroylpolyglutamate absorption was impaired in the ZD group, as indicated by the reduced area under the plasma folate absorption curve. Likewise, significantly lower plasma folate concentration was determined at various time-intervals following pteroylpolyglutamate ingestion in the $\mathrm{ZD}$ group compared with the $\mathrm{PF}$ and $\mathrm{AL}$ groups (Fig. 1). The results of Expt 2 suggest that lumen $\gamma$-glutamyl hydrolase is also a $\mathrm{Zn}$ sensitive enzyme. In the lumen, $\gamma$-glutamyl hydrolase activity was significantly lower at zero-time and less activity was induced following pteroylpolyglutamate ingestion in the ZD group compared with the pair-fed control group (Table 4). The results of both experiments demonstrate that pancreatic and lumen $\gamma$-glutamyl hydrolases are highly sensitive to the $\mathrm{Zn}$ status of rats, the activity of both being 50-60\% lower in $\mathrm{Zn}$-deficient compared with control rats. Kesavan \& Noronha (1983) observed that, in rats, both pancreatic and lumen $\gamma$-glutamyl hydrolases have similar $\mathrm{pH}$ optima and that the activity of both increases following pteroylpolyglutamate ingestion. The finding that both enzymes are equally sensitive to dietary $\mathrm{Zn}$ deprivation supports the observations of Jagerstad \& Westesson (1974) and Kesavan \& Noronha (1983) that pancreas is the source of the lumen enzyme in the rat. The latter authors also observed that following pteroylpolyglutamate ingestion, peak lumen $\gamma$-glutamyl hydrolase activity occurred concurrently with the peak rise in plasma folate concentration. Similar results were obtained in the present study (Fig. 1; Table 4), indicating that lumen $\gamma$-glutamyl hydrolase is active in the hydrolysis of pteroylpolyglutamate.

The present results suggest that as a consequence of reduced $\gamma$-glutamyl hydrolase activity in $\mathrm{Zn-deficient} \mathrm{rats,} \mathrm{pteroylpolyglutamate} \mathrm{hydrolysis} \mathrm{is} \mathrm{impaired.} \mathrm{This} \mathrm{is} \mathrm{indicated}$ by the smaller increase in plasma folate concentration that occurred following ingestion of pteroylpolyglutamate in ZD rats compared with $\mathrm{PF}$ and $\mathrm{AL}$ control rats. Similarly, Chandler et al. (1986) suggested that, in human beings, brush-border $\gamma$-glutamyl hydrolase activity and dietary folate availability are influenced by intestinal $\mathrm{Zn}$ levels. However, absorption rather than hydrolysis is considered the rate-limiting step in folate metabolism in man (Reisenauer \& Halsted, 1987) and in rats (Dhar et al. 1977; Rosenberg \& Selhub, 1986). Hydrolysis is reported as rate-limiting in aged rats (Kesavan \& Noronha, 1983) and may be rate-limiting in $\mathrm{Zn}$-deficient rats. $\mathrm{Zn}$ may also have a role in the transfer of absorbable folate across the gut wall. In rats receiving the vitamin in the monoglutamyl form, $\mathrm{Zn}$ supplementation enhanced blood folate levels (Fuller et al. 1988). Therefore, it is 
possible that $\mathrm{Zn}$ deficiency reduces the rates of both pteroylpolyglutamate hydrolysis and pteroylmonoglutamate absorption. Increased investigation of the role of $\mathrm{Zn}$ in the hydrolysis and absorption of dietary folates is required to elucidate further the effect of $\mathrm{Zn}$ deficiency on folate metabolism.

\section{REFERENCES}

American Institute of Nutrition (1977). Standards for nutritional studies report. Journal of Nutrition 107, 1340-1348.

Baugh, C. M., Krumdieck, C. L., Baker, H. J. \& Butterworth, C. E. (1971). Studies on the absorption and metabolism of folic acid. Journal of Clinical Investigation 50, 2009-2021.

Blakley, R. L. (1987). Nomenclature and symbols for folic acid and related compounds. Recommendations 1986. European Journal of Biochemistry 168, 251-253.

Butterworth, C. E., Baugh, C. M. \& Krumdieck, C. L. (1969). A study of folate absorption and metabolism in man utilizing carbon-14-labelled polyglutamates synthesized by the solid phase method. Journal of Clinical Investigation 48, 1131-1142.

Butterworth, C. E., Hatch, K., Cole, P., Sauberlich, H. E., Tamura, T., Cornwell, P. E. \& Soong, S. J. (1988). Zinc concentration in plasma and erythrocytes of subjects receiving folic acid supplementation. American Journal of Clinical Nutrition 47, 484-486.

Butterworth, C. E., Santini, R. \& Frommeyer, W. B. (1963). The pteroylglutamate components of American diets as determined by chromatographic fractionation. Journal of Clinical Investigation 4, 1929-1939.

Chandler, C. J., Wang, T. T. Y. \& Halsted, C. H. (1986). Pteroylpolyglutamate hydrolase from human jejunal brush borders. Journal of Biological Chemistry 261, 928-933.

Day, B. P. F. \& Gregory, J. F. (1984). Characteristics of human, pig and rat intestinal folacin conjugases. Federation Proceedings 43, 986.

Dhar, G. J., Selhub, J., Gay, C. \& Rosenberg, I. (1977). Direct in vivo demonstration of the sequence of events in intestinal polyglutamyl folate absorption. Clinical Research 25, 309A.

Dwivedi, C. M., Dormody, J., Chandler, C., Wang, T. \& Halsted, C. H. (1983). Characteristics of human intestinal folate conjugases. Federation Proceedings 42, 667.

Elsenhans, B., Ahmad, O. \& Rosenberg, I. H. (1984). Isolation and characterization of pteroylpolyglutamate hydrolase from rat intestinal mucosa. Journal of Biological Chemistry 259, 6364-6368.

Fuller, N. J., Evans, P. H., Howlett, M. \& Bates, C. J. (1988). The effects of dietary folate and zinc on the outcome of pregnancy and early growth in rats. British Journal of Nutrition 59, 251-259.

Ghishan, F. K., Said, H. M., Wilson, P. C., Murrell, J. E. \& Greene, H. L. (1986). Intestinal transport of zinc and folic acid: a mutual inhibitory effect. American Journal of Clinical Nutrition 43, 258-262.

Halsted, C. H. (1979). The intestinal absorption of folates. American Journal of Clinical Nutrition 32, 846-855.

Halsted, C. H., Chandler, C., Wang, T., Beer, W. H.\& Dwivedi, C. (1983). Brush border folate conjugase : a zinc activated enzyme. Gastroenterology 84, 1179.

Halsted, C. H., Chandler, C. J., Wang, T. T. \& Cerda, J. J. (1985). Human jejunal pteroylpolyglutamyl hydrolases: clinical and biochemical distinctions. Clinical Research 33, 526A.

Jagerstad, M. \& Westesson, A.-K. (1974). The hydrolysis of pteroylpolyglutamates in the small intestine. Scandinavian Journal of Gastroenterology 9, 639-643.

Keating, J. N., Wada, L., Stokstad, E. L. R. \& King, J. C. (1987). Folic acid : effect on zine absorption in humans and in the rat. American Journal of Clinical Nutrition 46, 835-839.

Kesavan, V. \& Noronha, J. M. (1983). Folate malabsorption in aged rats related to low levels of pancreatic folyl conjugase. American Journal of Clinical Nutrition 37, 262-267.

Lowry, O. H., Rosebrough, N. J., Farr, A. L. \& Randall, R. J. (1951). Protein measurement with the folin phenol reagent. Journal of Biological Chemistry 193, 265-275.

Lukaski, H. C., Bolonchuk, W. W. \& Milne, D. B. (1986). Functional assessment of zinc nutriture using changes in plasma zinc after exercise in men supplemented with folic acid. Federation Proceedings 45, 973.

Milne, D. B., Canfield, W. K., Mahalko, J. R. \& Sandstead, H. H. (1984). Effects of oral folic acid supplements on zinc, copper and iron absorption and excretion. American Journal of Clinical Nutrition 39, 535-539.

Perry, J. \& Chanarin, I. (1968). Absorption and utilization of polyglutamyl forms of folate in man. British Medical Journal 4, 546-549.

Reisenauer, A. M. \& Halsted, C. H. (1987). Human folate requirements. Journal of Nutrition 117, 600-602.

Reisenauer, A. M., Krumdieck, C. L. \& Halsted, C. H. (1977). Folate conjugase: two separate activities in human jejunum. Science 198, 196-197.

Rosenberg, I. H. \& Selhub, J. (1986). Intestinal absorption of folates. In Folates and Pteridins, vol. 3, pp. 147-176 [R. L. Blakley and V. M. Whitehead, editors]. New York: John Wiley \& Sons.

Ryan, T. A., Joiner, B. L. \& Ryan, B. F. (1976). Minitab Student Handbook. Boston, MA: Duxbury Press.

Sandstead, H., Cherry, F., Bazzano, G., Johnson, L., Bunce, H., Milne, D., Mahalko, J. \& Batson, H. (1987). Folate-zinc interaction in human pregnancy. Federation Proceedings 46, 748. 
Scott, J. M., Ghanta, V. \& Herbert, V. (1974). Trouble free microbiologic serum and red cell folate assays. American Journal of Medical Technology 40, 125-134.

Silink, M., Reddel, R., Bethel, M. \& Rowe, P. B. (1975). $\gamma$-Glutamyl hydrolase (conjugase); purification and properties of the bovine hepatic enzyme. Journal of Biological Chemistry 250, 5982-5994.

Simmer, K., Iles, C. A., James, C. \& Thompson, R. P. H. (1987). Are iron-folate supplements harmful? American Journal of Clinical Nutrition 45, 122-125.

Tamura, T., Kaiser, L. L., Watson, J. E., Halsted, C. H., Hurley, L. S. \& Stokstad, E. L. R. (1987). Increased methionine synthetase activity in zinc-deficient rat liver, Archives of Biochemistry and Biophysics 256, 31 I-316.

Tamura, T., Shane, B., Baer, M. T., King, J. C., Margen, S. \& Stokstad, E. L. R. (1978). Absorption of monoand polyglutamyl folates in zinc-depleted man. American Joumal of Clinical Nutrition 31, 1984-1987.

Wada, L., Keating, S., King, J. C. \& Stokstad, E. L. R. (1986). Effect of folic acid on zinc absorption. Federation Proceedings 45, 1081 .

Wang, T. T. Y., Reisenauer, A. M. \& Halsted, C. H. (1985). Comparison of folate conjugase activities in human, pig, rat and monkey intestine. Journal of Nutrition 115, 814-819.

Williams, R. B. \& Mills, C. F. (1970). The experimental production of zinc deficiency in the rat. British Journal of Nutrition 24, 989-1003.

Williams, R. B., Mills, C. F. \& Davidson, R. J. L. (1973). Relationships between zinc deficiency and folic acid status of the rat. Proceedings of the Nutrition Society 32, 2A-3A.

Wilson, P. C., Greene, H. L., Murrell, J. E. \& Ghishan, F. K. (1983). The effect of folic acid on the intestinal absorption of zinc. Clinical Research 31, 760A.

Wilson, S. D. \& Horne, D. W. (1982). Use of glycerol-cryoprotected Lactobacillus casei for microbiological assay of folic acid. Clinical Chemistry 28, 1198-1200. 